\title{
Evaluation of Dietary Fiber and the Effect on Physicochemical Properties of Foods
}

\author{
Ahmed M A Hamad \\ High Institute for Medical Profession Albaida-Libya
}

Article Info

Volume 8, Issue 3

Page Number : 421-433

\section{Publication Issue}

May-June-2021

\section{Article History}

Accepted : 15 May 2021

Published : 30 May 2021

\section{ABSTRACT}

Dietary fiber considered a main ingredient of food products. The Increased attention of DF in food products is caused by an increased interest in developing health foods, Dietary fiber is consisting polysaccharides and oligosaccharides, and cellulose hemicelluloses, resistant starch, pectin substances, and gums, also the of DF has wide application in food processing because its technological properties. for exampleDF could extend the shelf-life of the product by the water-holding capacity the DF important in the human diet. the food rich in fibre such as cereals, nuts, fruits and vegetables have a positive effect on health since their consumption help in prevent many diseases. Dietary fibre can be used in many functional foods like drinks, beverages, bakery, and meat products. effect of different processing treatments (like cooking, canning, grinding, boiling, frying) change the physico-chemical properties of dietary fibre and improves their functionality. Dietary fibre can be analytical by different methods, mainly by: enzymic gravimetric and enzymic- chemical methods. This paper presents the classification, applications, and functions of dietary fibre in different food products.

Keywords : Dietary Fibre, Classification, Physico-Chemical, Analysis, Processing, Functional Foods

\section{INTRODUCTION}

Dietary fiber is defined as carbohydrate material of plant origin that cannot be digested by the enzymes by human it is contain compounds like cellulose, hemicelluloses, pectin's, and gums. Some of these materials cannot digested in the lower gastrointestinal tract by the microbial flora of the colon. Fibers may be soluble or insoluble and have different physiological effects; i.e. cellulose speeds transit of material though the gut while gel-forming fibers may actually retard transit time. The term 'dietary fibre' (DF) first appeared in 1953 andreferred to hemicelluloses, cellulose and lignin Hipsley (1953) Dietary fibre is a group of food components which is resistant to digestive enzymes and found mainly in cereals, fruits and vegetables Dietary fibre which indigestiblein human small intestinal, on the other 
hand digested completely or partially fermented in the largeintestine, is examined in two groups: watersoluble and water insoluble organic compounds.[SelinOzgoz et al (2014).Diet high in fiber generally reflects a healthier life style. Despite the healthful influence dietary fiber can have on reducing risk of chronic disease, the intake remains low worldwide. Increasing fiberconsumption in the diet has been a difficult challenge, as fiber sources usually used in foods have not, generally speaking, made high fiber foods with high quality taste and textural properties. It is important from food product development standpoint that high fiber ingredients, not only made using high fiber, but also provide enhanced functional properties to make high-fiber foods taste better, thus encouraging continued high fiber intake Tungland, \& Meyer, (2002).

\section{Definition}

Dietary fibre has long history, its term originating with Hipsley (1953) who coined dietary fibre as a nondigestable constituents making up the plant cell wall and further its definition has seen several revisions. Botanists define fibre as a part of the plant organs, chemical analysts as a group of chemical compounds, consumer as a substance with beneficial effects on human health and for the dietetic and chemical industries dietary fibre is a subject of marketing. Later dietary fibre was defined as a ubiquitous component of plant foods and includes materials of diverse chemical and morphological structure, resistant to the action of human alimentary enzymes. Kay,. (1982).

In 1981, the Association of Official Analytical Chemists (AOAC) consensus definition referred primarily to the remnantsof plant cells resistant to hydrolysis by alimentaryenzymes of man but it was abandoned due to several analyticaland physiological considerations AOAC(2006) .Dietary fibre means carbohydrate polymers with ten or more monomeric units which are not hydrolysed by the endogenous enzymes in the small intestine of humans and belong to the following categories:

Edible carbohydrate polymers naturally occurring in the food as consumed, carbohydrate polymers, which have been obtained from food raw material by physiological, enzymic or chemical means and which have been shown to have a physiological effect of benefit to health as demonstrated by generally accepted scientific evidence to competent authorities, synthetic carbohydrate polymers. The recommended methods of analysis to comply with this definition are also now in the finalisation stage. A review of the available and recommended methods has now been prepared by Codex (2009).Phillips, \& Cui, (2011)substances from plant undigested by human enzymes contain plant cell wall substances (cellulose, hernicelluloses pectin, and lignin) and intracellular polysaccharides such as gums and mucilage's. Trowell, et al (1976).Substances resists digestion and absorption is a carbohydrate and that termed Dietary fiberand could has microbial fermentation in the large intestine. Lattimer, \&Haub, (2010) In a simplified definition, dietary fiber is a carbohydrate that resists digestion and absorption and may or may not undergo microbial fermentation in the large intestine.SelinOzgoz et al (2014)

\section{Classification of dietary fiber-3}

Many different classification, accordance to their function in the plant, or on the type of polysaccharide, and their simulated gastrointestinal solubility on site of digestion and based on products of digestion and physiological classification. so there is no satisfactory classifications . Classification for dietary fibre has been to differentiate dietary components on their solubility in a buffer at a defined $\mathrm{pH}$, andor their fermentability in an invitro system using an aqueous enzyme solution representative of human alimentary enzymes. Thus most appropriately dietary fibre is 
classified into two categories such as waterinsoluble/less fermented fibers: cellulose, hemicelluloses, lignin and the water- soluble/well fermented fibres: pectin, gums and mucilage's[Sánchez-Muniz, (2012)DF can be classified by many possible ways such as on the basis of source that can be further categorized into plant polysaccharides, animal polysaccharides, and polysaccharides derived from native or synthetic sources. On the basis of structure, polysaccharides can be categorized into polysaccharides having linear or nonlinear molecular structure. On the basis of solubility they are soluble or no soluble. Other basic groupings are by properties, their applications, and on the basis of polysaccharide chemistryBeMiller, (2001)

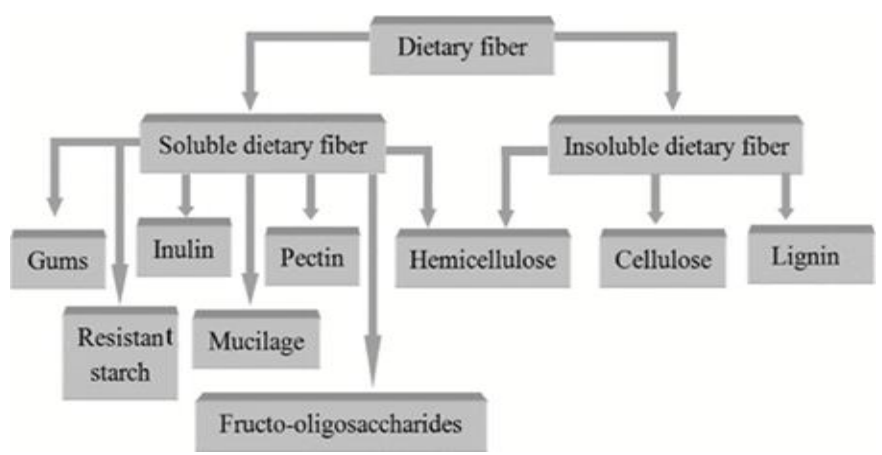

Figure 1. Classification of dietary fiber according solubility

\section{3-1 Cellulose}

Is the most abundant polysaccharide found in nature. It is a major component of the cell wall of most plants and hence, present in fruits, vegetables and cereals. It is a polymer branched polysaccharide insoluble and resistant to digestion by human enzymes. Cellulose forms main quantity of the dietary fiber in grains and fruit and in vegetables, nuts. Wheat bran is good source of cellulose - insoluble fiber. it has an ability to bind water which helps in increasing fecal volume and thus promoting regular bowel movements. also humans are not able to digest cellulose ,About $50 \%$ of cellulose is degraded by natural fermentation in colon and produce significant amount of short-chain fatty acids which feed our intestinal cells.Tungland, \& Meyer, (2002).Celluloseis produced by some microorganisms like fungi and bacteria and consider major component of the cell walls plants, and cellulose important material in the textile and wood fiber industries, and food qualityWada, et al (2008) .Cellulose is more commonly considered as a polymer of glucose because cellobiose consists of two molecules of glucose. The chemical formula of cellulose is $(\mathrm{C} 6 \mathrm{H} 10 \mathrm{O} 5)$ nCellulose is a linear homopolymer composed of the (1-4)-linked units glucopyranose unitsCellulose is a linear polymer produced by plants.Harmsen, et al (2010) cellulose application in many fields and industries like food processing and because awide request in the markets become expand fast application in industryYan, et al (2009)

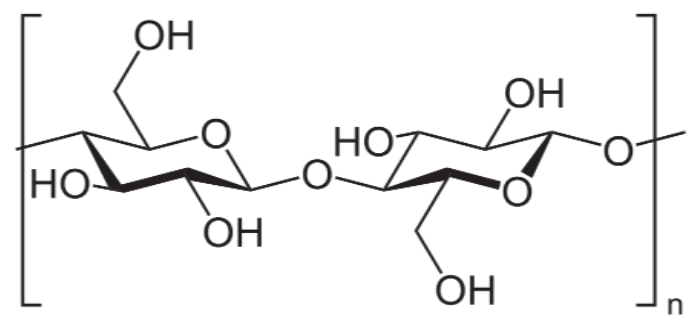

Figure 2. The structure of Cellulose

\section{3-2Hemicellulose}

It is polysaccharidessoluble in aqueous alkali after removal of water-soluble. It is contain glucose units with $\beta-1,4$ glucosidic linkages, hemicelluloses (also a polysaccharide) consists of shorter chains, contain variety of sugars xylose, mannose, galactose, rhamnose, and arabinosehemicellulose is a branched polymer, while cellulose is unbranched Kay, (1982).hemicellulose is mean group of polysaccharides such as arabino-xylans, gluco-mannans, galactans which present in the plant cell wall differnt in structure and composition that according to the source and the method of extractionHarmsen, et al (2010)In softwood hemicelluloses are galactoglucomannan, glucomannan and arabinoglucuronoxylan also 
hemicelluloses in other softwood are arabinogalactan, xyloglucan and glucans.Laine, (2005).

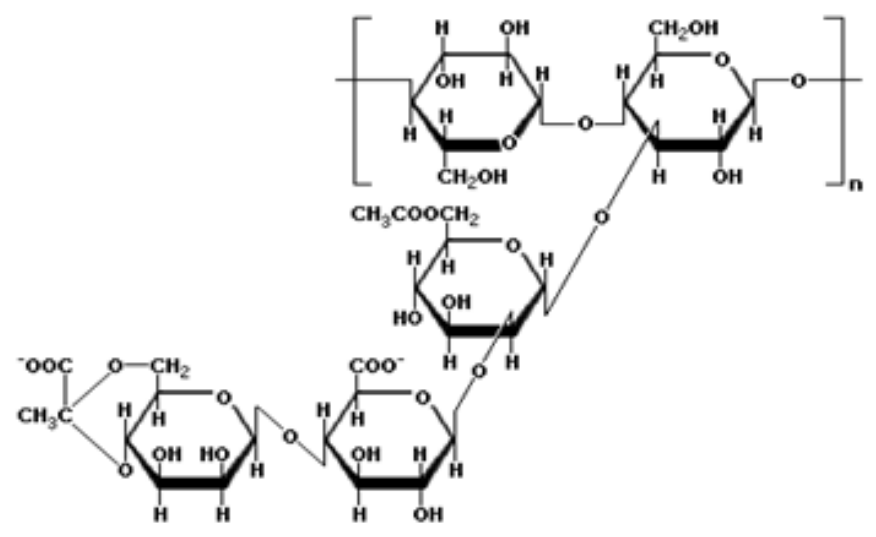

Figure 3. The structure of Hemicellulose

3-3Lignin

It is in the plant cell wall with cellulose and hemicelluloses. It consider reinforcement for the matrix and provides rigidity, prevent water and resistance against microbial attack. Its quantity in plants ranges from $15 \%$ to $36 \%$ by mass Bujanovic, et al (2010) Lignin is natural polymer phenyl propane units of p-coumaryl alcohol, coniferyl alcohol and sinapyl alcohol. It is an amorphous threedimensional. Harmsen, et al (2010)

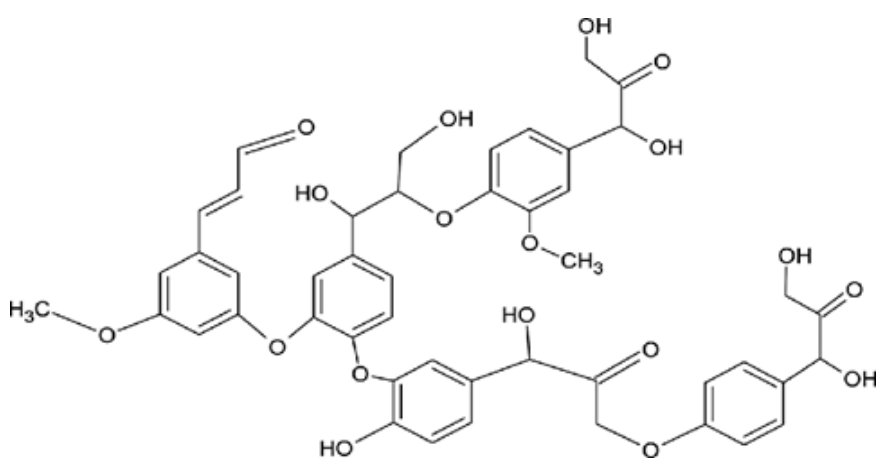

Figure 4. The structure of Lignin

\section{3-4 Pectin}

The main polysaccharides constituent is Dgalacturonic acid. They are structural components of plant cell walls and act as intercellular cementing substances. Pectin has a strong degree of soluble and for the ability to take shape almost the metabolism of coli bacteria and sugars offset this topic because of the soluble reduces the rate of gastric emptying and minimize the impact on the intestinal transit time. This explains their hypoglycemic properties Jenkins, et al (1978)Pectins are pectic polysaccharides, homogalacturonan, rhamnogalacturonan-I and substituted galacturonans in cell wall and linkege is 1,4-linked $\alpha$-Dgalactosyluronic residuesSharma, et al (2006)pectine presence as polygalacturonic acids in fruits, vegetables, legumes, and roots commercial pectin from byprouducts citrus peels and pomace of fruitsW. DeVries. (2004) pectins are the component rhamnogalacturonan or group of components hamnogalacturonans, galactans and arabinanLaine, (2005).

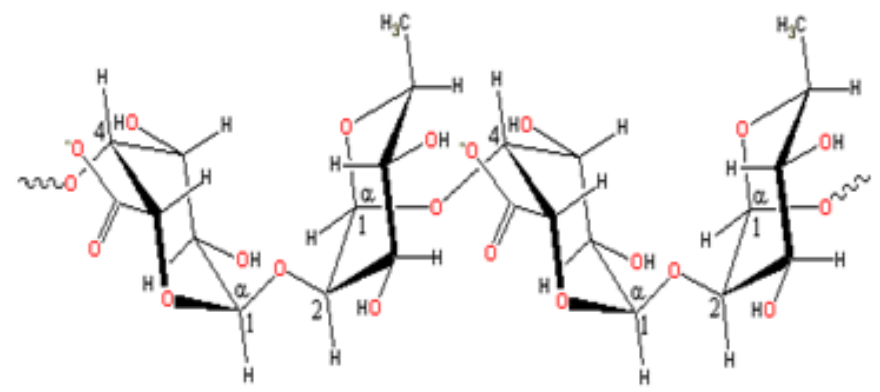

Figure 5. The structure of pectin

Gums are products formed following injury to the plant or bad conditions, such as drought, by a breakdown of cell walls, Mucilage's are generally normal products of metabolism, formed within the cells of plants (intracellular formation). Gums readily dissolve in water, whereas, mucilage form slimy masses. Mucilage's are physiological products of plants. it is polymers of a monosaccharide or mixed monosaccharide's and many of them are combined with uronic acids. Gums and mucilage's have similar constituents and on hydrolysis yield a mixture of sugars and uronic acids. Gums and mucilage's contain hydrophilic molecules, which can combine with water to form viscous solutions or gelsReddy, \&Manjunath. (2013)Gums are substance formed as result of injury in the plant like a breakdown of cell walls and mucilages normal productsGums and 
mucilages are plant hydrocolloids.and it is polymers of a monosaccharide joined with uronic acids and it has the same composition and can hydrolysis to sugers and uronicacids.also has hydrophilic molecules and the properties of gums influences by the nature compounds in gums.[Deogade, $U$ et al 2012]gums are polymers of monosaccharide units joined by glucocidic bonds.it is water soluble or absorb water and give a viscous solution or jelly on hydrolysis gives arabinose, galactose, mannose and glucuronic acid, Krishna, et al (2011)

\section{Physicochemical properties of dietary fiber}

\section{4-1 Water-holding capacity}

The water-holding capacity of dietary fiber most important effects on the intestine and can determine The fiber saturation capacity by the chemistry and morphology of the macromolecules and by the $\mathrm{pH}$ and electrolyte concentration of the surrounding medium and can define Water holding capacity as the amount of water that is retained by $1 \mathrm{~g}$ of dry fibres under specified conditions of temperature, time soaked, and duration and speed of centrifugation of dietary fiber, Fleury, \& Lahaye, (1991).Polysaccharides soluble and insoluble have free hydroxyl-groups then it has ability to hold water because it can form hydrogen bonds with water Spiller, (2001). Water-holding capacity (WHC) Water-holding capacity is the ability of a moist material to retain water when subjected to an external centrifugal gravity force or compression. It consists of the sum of linked water, hydrodynamic water and physically trappedwater, the latter of which contributes most to this capacity Torruco-Uco, et al (2009)

\section{4-2 Solubility}

Dietary fiber can be divided into two types: soluble (pectin and gum) and insoluble (cellulose, lignin). Soluble and insoluble of dietary fiber decides technological functions and physiological effects of soluble fiber is responsible for the increased viscosity and reduces blood sugar and cholesterol plasma response. featuring fiber is soluble by-porous, low density and are associated with an increase in the largest stool and a decrease in intestinal transit in the food processing operations segment, the introduction of soluble fiber in food products is more useful, as it provides viscosity, and the ability to form gels and or as emulsions, compared with fiber is solubleTungland, \& Meyer, (2002).Two types of dietary fiber soluble dietary fiber and insoluble fiber,the Soluble fiber(pectins, gums, inulin-type fructans and some hemicelluloses) dissolves in water forming viscous gels and can easily fermented by the microflora of the large intestine insoluble fibers do not form gels( lignin, cellulose and some hemicelluloses Wong, , \& Jenkins, (2007).

\section{4-3 Hydration property}

The clear definition and standards for measurement of properties were major considerations for hydration property Water absorption property of dietary fiber is an important determinant of stool bulking effect, which is due to the manner in which water is held, rather than the absolute amount held. Strongly bound water has been found to have no effect on stool weight, where as loosely associated water readily increases stool weight. The maximum amount of water that the fiber can hold is a function of the fiber source and its chemical, physical and structural characteristics Raghavarao, et al (2008).The hydration properties of insoluble materials defined accordance to the methods used. becausedifferent methods refer to different mechanisms and different hydration properties of the samples of water 
associated with the fibres. These properties can be grouped under the name of hydration properties.therefore it is important factor limit the physiological functionality of the DFalong the digestivetract,Frazzoli, A. (2007). Water holding capacity is defined by the quantity of water that is bound to the fibers without the application of any external force.Raghavarao, et al (2008)

\section{4-4 Swelling capacity}

Swelling property is defined as ratio of volume occupied when the sample is immersed in excess of water after equilibration to the actual weight. Accurately weighed dry sample $(0.2 \mathrm{~g})$ was taken in a graduated test tube, around $10 \mathrm{ml}$ of water was added and hydrated for $18 \mathrm{~h}$. After $18 \mathrm{~h}$, the final volume attained by fiber was measured Raghavarao, et al (2008) . Three swelling capacities were also determined by weighing $1 \mathrm{~g}$ of fiber into graduated glass cylinder and the initial volume occupied by the fiber recorded. Thereafter, $30 \mathrm{ml}$ of different buffers were added to maintain the $\mathrm{pH}$ at 6.6, 1.8 and 8.7, and the samples were allowed to swell for $7 \mathrm{~min}, 135 \mathrm{~min}$ and $60 \mathrm{~min}$ respectively.Daou, \& Zhang, (2012). The final volumes were noted and expressed as $\mathrm{ml}$ of swollen sample per gram of dry initial sample.

\section{4-5 Viscosity}

Defined viscosity of a fluid is a measure of its resistance to gradual deformation by shear stress or tensile stress.For liquids, it corresponds to the informal concept of "thickness most polysaccharide solutions exhibit non-Newtonian flow and an increased shear rate can increase or decrease viscosity water soluble fibres are the major component that would increase the viscosity of a solution ( showed that defatted rice bran has low viscosity approximately $1.25 \mathrm{cps}$ at $7 \%$ fibre in water), because it contains only $9 \%$ soluble fibre. Viscosity increases with an increased fibre concentration but decreases with the temperature of a solution of dietary fibre. Abdul-Hamid, \& Luan, . (2000). -Elleuch, et al (2008)showed that peach and date dietary fibre suspensions performed as pseudoplastic fluids, whoseapparent viscosity or consistency decreases instantaneously with an increasein shear rate, as described by the power-law model $(\Gamma=\mathrm{K} \gamma \mathrm{n})$. The degree of the pseudo plasticbehavior can be measured by the flow behavior index (n)

\section{Effect of food processing on the properties dietary fibre}

Dietary fiber using in food industry for several reasons, including increased and improved fiber intake infood products and also to improve product quality of the characteristics of sensual textures and viscosity, shelf-life and this includes major products and by-products of the foods industries that can be used as a source of fiber for inclusion in processed foods. It can include these byproducts of waste from the fruit and vegetable industries (such as pomace, peel or skin), and industry grains (such as wheat bran, rice bran), and can combine these byproducts of fiber in food and cheap products, is bulking agents - caloric. These can be used to replace part of the flour or fat and enhances the retention of water and oil emulsion to improve steadily and or oxidation. However, the maximum incorporation of fibers in different food products differs because it may cause undesirable changes in the color and texture of foods. Dietary fiber addition to extend the freshness of bakery products because of its ability to retain water. Fiber can adjust the size of a loaf of bread, flexibility and suppleness of a piece of bread and packets of bread loaf. and enhanced into dairy products affect the gelation, sensory and rheological properties ,Mudgil, \& Barak, (2013).

Wheat bran is rich in dietary fiber, which improves the flour nutritional content and also endows the flour with a richer flavor. However, a high content of 
insoluble dietary bran fiber may badly compromise the processing and edible quality of flour products. One study was conducted to explore ways to decrease the negative effects by using fermented bran, which showed longer dough extensibility and stability and better overall steam bread texture. \$is provided an innovative way to increase the dietary fiber content of steam bread. Research demonstrated how the complex additives including sodium carboxymethyl cellulose (CMC-Na) affect the storage property of steamed bread during frozen dough storage. results showed that adding complex additives could enhance gas-holding capacity of gluten and maintain yeast activity upon frozen storage. Another research was performed to investigate the quality of fresh wet noodles made from different flour milling streams. \$e basic composition, texture properties, cooking characteristics, and moisture status of the noodles were compared. results indicated that as storage time increased, the springiness of fresh wet noodles gradually decreased, while the hardness increased,Guo, et al (2018)

Food processing includethermal treatments like boiling, cooking and canning. this treatments cause change in the texture of the fiber.Rodríguez, et al (2006) .The different processing treatments have different effects on the insoluble DF, and soluble DF and total DF of selected cereals and legumes. The changes after various treatments. In samples with high protein content like soya beans, both and insoluble DF and soluble DF increases with thermal treatments that may be attributed to the production of Millard reaction productsAzizah, \&Zainon, (1997).Changes of heat treatment in dietary fiber content depend on several factors, the most important of grain and beans type, and the method and duration of treatment. In addition, the results obtained also vary with the analytical method applied. For foods that are not eaten raw, such as beans, and data on dietary fiber content of processedfoods are much more than those of the importance of raw foodscooking five types of beans by the three different methods. Ordinary and microwave cooking reduced NDF by $21.7-27.3 \%$ and 21.0 24.5\%respectively28.5-35.3\%reduction in NDF content was observed upon cooking the food legumes in a pressure cooker. were cooked for different time periods in order to achieve a uniform degree of tenderness, from the result, that the dietary fibre components of these five food legumes were reduced to various extents as a result of cooking by the three different methods, In order to minimize the losses of dietary fibre,it is suggested that legumes should be cooked, either by the ordinary method or in a microwave oven instead of a pressure cooker.Shah, (2004).wheat and barley flours heating at $100^{\circ} \mathrm{C}$ increase of water extracts viscosities as a result of conversion of the insoluble dietary fiber into soluble dietary fiberCăpriță, et al (2011)The green leafy vegetable contain quantity of protein and dietary fibre,cooking and blanching have effect on the nutritional values of the vegetables cooking the leafy vegetables caused only small changes in total dietary fibre contents of the samples.thateffect is redistribution from insoluble to soluble fibre components Ilelaboye, et al . (2013).Thermal processing of vegetables had a significant effect on changes in contents of dietary fiber. The direction of these changes was dependent on the type of applied thermal processing. Boiled vegetables were characterized by significantly higher contents of dietary fiber and its fractions in comparison to steamed vegetables. An increased proportion of the cellulose and lignin fractions was found in cabbages after thermal processing in water Komolka et al (2012).

\section{Application dietary fibre in food industry}

The enrichment of foods with dietary fibres is an effective way to enhance nutritional and physiological aspects and to promote functionality by influencing rheological and thermal properties of the 
final product, Yangilar, (2013).Dietary fiber has good physiological influences and have certain salutary properties which can improve the quality of food products like eating quality, and shelf stability the gums and pectin, added technological value to food products fiber as several advantages, particularly for the low-viscosity fibers,Tungland, \& Meyer, (2002). The by-products of food processing fruits and vegetables or algae and cereal good and cheap source of dietary fiber in recent research concerning dietary fibres, it is made wide knowledge of their functional properties added to food products that provide advantageous dietary fibre and bioactive compounds. They serve as non-caloric bulking agents, enhance water and oil retention, and improve emulsion and oxidative stabilityElleuch et al (2011).The production of hamburgers with partial substitution of beef with cashew apple residue improved the product, which presented high nutritional quality and was rich in or had high dietary fiber content and low in fat when compared to conventional ones, and was higher in proteins when compared to vegetable hamburgers. They produced a good yield and a lower rate of shortening when compared to the control sample. The addition of up to $10.7 \%$ of cashew apple residue did not change significantly the sensorial impacts in terms of taste when compared to the control sample. Therefore, the product prepared with partial substitution of meat with this residue can be considered a very feasible product to be commercialized in food Market.Pinho et al (2011) .Improvement in nutritional properties. of beef burgers and increase in protien content (16.61\%) and decreased energy value by the addition of orange albedo fiber and burgers with adding albedo become less hard and the cooking properties were improved,Eldemery,. (2010). The addition fibre of both pea and potato to reduced-fat beef burgers increased their overall acceptability to a level similar to that of a normal fat beef burger. A $3 \% \mathrm{w} / \mathrm{w}$ addition of fibres to beef burger formulations had a more favorable effect than a $1.5 \% \mathrm{w} / \mathrm{w}$ addition rate.
The addition of the fibres to the reduced-fat beef burger formulations prolonged the flavor intensity, The concentrations of flavor volatiles in reduced-fat beef burgers containing both pea and potato fibres at a $1.5 \% \mathrm{w} / \mathrm{w}$ addition level were similar to those in normal fat beef burgers,McDonagh et al (2004).The addition of dietary fibre to the bread making process help to enhancement of modification of textural properties, oil and water holding capacities, reduction of syneresis, also dietary fibre could effect in certain characteristics like water-binding, antisticking, fat mimicking and thickening capacities. and gel-forming, this improves the shelf-life of bread, especially when included in food productsKurek, \&Wyrwisz, (2015).Extracted lemon fiber from lemon pomace and enhancement the bread.the hardness of bread increased with the increase of Lemon fiber but the cohesiveness, springiness, and specific volume decreased with the fiber substitution. Chang, \&Shiau, (2015).In food products nutritional values, antioxidant status, rheological properties, and sensory attributes of baked products affect by addition of different types of fibers;Sivam, et al (2010). Dietary fiber has health benefits like lowering the level of cholesterol in the body and positive effect on bowel function and controlling blood sugar levels also dietary fiber has influence on rheological parameters of dough and shelf-life of bread and on sensory characteristics of breadKurek, \&Wyrwisz, (2015). While apple fiber is good dietary fiber source it can use in bread baking, apple fiber also can be added into cookie and muffin at a replacement level of $4 \%$ or less without large adverse effects on cookie and muffin qualityChen et al (1988). whereasthe cake recipe added different levels of $0,5,10,15,20 \%$,Oat fiber and $30 \%(\mathrm{w} / \mathrm{w}$, flour basis) that increasing the level of oat fiber result increase in batter density and consistency and cake volume also the cake crust and crumb became darker. addition of $20 \%$ oat fiber to cake can produce acceptable sensory characteristicsMajzoobiet al (2015) .Rheological and visco-elastic parameters of starch, gluten and flour 
systems affected by the addition of cellulose fibre also the size of cellulose fibre addition cause significant differences in water absorption, stickiness of flour, Goldstein et al (2010).

This study evaluated the effect of the addition of four different types of dietary fibers on the rheological, physicochemical and sensory characteristics of yogurt. The four types of fibers (inulin, pea, oat and wheat) were added in the yogurt formulation in different proportions (1\%-2.5\%) using classical technology adapted to laboratory conditions. The obtained results showed that, the most viscous samples were obtained with wheat fibers addition ( $1 \%$ and $1.5 \%$ ), while the best viscous characteristics were obtained for the samples with oat fibers addition (2\% and $2.5 \%)$. The lowest syneresis value $(38.86 \pm 0.2)$ were observed for the samples with $1.5 \%$ pea fibers addition. Yogurt samples with the highest acceptance scores were samples with $2 \%$ wheat fibers and respectively with $2.5 \%$ pea fibers addition. All the tested fibers were compatible with the yogurt-manufacturing process. Therefore, the fibers addition in yogurt could be considered an alternative to incorporate dietary fibers in the human diet.Dabija, et al (2018)

Fibre and yogurt are well known for their beneficial health effects, together will constitute a functional food with commercial applications. this the conclude of studied the effect of fortification with date fibre, a by-product of date syrup production, on fresh yogurt. yogurt fortified with 1.5, 3.0 and 4.5\% date fibre and yogurt with $1.5 \%$ wheat bran were prepared. Yogurt fortified with $3 \%$ date fibre control yogurt (without fibre) resulted with similar sourness, sweetness, firmness, smoothness and overall acceptability as the control yogurt,Hashim, et al (2009).Fiber can be used for improvement of some functional properties such as texture, water holding capacity, oil holding capacity, emulsification andgel formation, bulking agent in reduced-sugar applications, and shelf-life of processed foods,Roc1 'oRodrı' guezet al ( 2006).whilst
Improved the texture, viscosity and reduced whey syneresis of yoghurts by enhancement of camel's yoghurts with orange fibers also the fermented camel milk with orange fibers fortification bacterial growth and survival of probiotic bacteria, $4.5 \%$ orange fiber is an correct quantity to add in camel's yoghurt production, it is gave the highest flavor, texture, appearance and overall acceptability scores to the yoghurt fortified with orange fiber than control,Ibrahim, \&Khalifa, (2015). The addition of orange and apple fibers into ice cream mixes yielded greater improvement in rheological properties and melting resistance compared with control and other experimental samples. However, the viability of B. lactis and taste-flavor scores were lower in samples with orange fiber. In the manufacture of probiotic ice cream, wheat fiber has potential to improve rheological and textural characteristics, while maintaining sensory

Properties and probiotic viability,Akalın et al (2018).

The results demonstrated that fibre-enriched pasta could be produced by adding up to 15 per cent of dietary fibre into regular semolina-based pasta formulation, leading to acceptable products with matching characteristics of texture and colour compared to commercial products. Among the three fibre sources, oat bran (OB), whole barleyflour, and resistant starch (RS) offered better characteristics of texture and taste, while RS featured the most desired golden colour. Although all three addition levels resulted in acceptable products, the lower addition level ( 5 per cent) led to the highest preference from the sensory panel, Makhlouf,et al (2019).

\section{VII.Conclusion}

Dietary fiber is plant material resistant to enzymatic digestion in human diet, It consisting cellulose, hemicelluloses, gums, mucilages,pectic substances and lignin etc. the main source of dietary fibre is in cereals, and nuts, fruits, vegetables. The methods of 
analysis and physico-chemical properties of dietary fibre are discussed in this paper. The diets with high content of fibre have been reported to have a positive effect on health. the effect of food processing on the dietary fiber properties enzymatic and thermal treatments, which effect in the composition of total fiber. combination of fibre can change the consistency, texture, rheological behavior and sensory of the end products. Fortification of fiber in breakfast cereals, bread, cookies, cakes, yogurt, beverages and meat products has been reported with favorable results. byproducts and pomace source of fibre enriched products at economical cost need immediate attention

\section{REFERENCES}

[1]. Hipsley, E. H. (1953). Dietary "fibre" and pregnancy toxaemia. British medical journal, 2(4833), 420.

[2]. Ötles, S., \&Ozgoz, S. (2014). Health effects of dietary fiber. ActascientiarumpolonorumTechnologiaaliment aria, 13(2), 191-202.

[3]. Tungland, B. C., \& Meyer, D. (2002). Nondigestibleoligo-and polysaccharides (Dietary Fiber): their physiology and role in human health and food. Comprehensive reviews in food science and food safety, 1(3), 90-109.

[4]. Kay RM. Dietary fibre. J Lipid Res. 1982

[5]. Horwitz, W. (2010). Official methods of analysis of AOAC International. Volume I, agricultural chemicals, contaminants, drugs/edited by William Horwitz. Gaithersburg (Maryland): AOAC International, 1997.

[6]. Phillips, G. O., \& Cui, S. W. (2011). An introduction: Evolution and finalisation of the regulatory definition of dietary fibre.

[7]. Trowell, H., Southgate, D. A. T., \&Wolever, T. M. S. (1976). Leeds, AR, Gassull, MA and Jenkins, DJA. Dietary fibre redefined: Lancet, 1, 967.
[8]. Lattimer, J. M., \&Haub, M. D. (2010). Effects of dietary fiber and its components on metabolic health. Nutrients, 2(12), 1266-1289.

[9]. Sánchez-Muniz, F. J. (2012). Dietary fibre and cardiovascular health. Nutricionhospitalaria, 27(1), 31-45.

[10]. BeMiller, J. N. (2001). Classification, structure, and chemistry of polysaccharides of foods. FOOD SCIENCE AND TECHNOLOGYNEW YORK-MARCEL DEKKER-, 603-612.

[11]. Wada, M., Nishiyama, Y., Chanzy, H., Forsyth, T., \&Langan, P. (2008). The structure of celluloses. Powder Diffraction, 23(2), 92-95.

[12]. Harmsen, P. F. H., Huijgen, W., Bermudez, L., \& Bakker, R. (2010). Literature review of physical and chemical pretreatment processes for lignocellulosic biomass (No. 1184). Wageningen UR-Food \&Biobased Research.

[13]. Yan, F. Y., Krishniah, D. U. D. U. K. U., Rajin, M., \& Bono, A. (2009). Cellulose extraction from palm kernel cake using liquid phase oxidation. Journal of Engineering Science and Technology, 4(1), 57-68.

[14]. Laine, C. (2005). Structures of hemicelluloses and pectins in wood and pulp. Helsinki University of Technology.

[15]. Bujanovic, B., Ralph, S., Reiner, R., Hirth, K., \&Atalla, R. (2010). Polyoxometalates in oxidative delignification of chemical pulps: Effect on lignin. Materials, 3(3), 1888-1903.

[16]. Jenkins, D. J., Wolever, T. M., Leeds, A. R., Gassull, M. A., Haisman, P., Dilawari, J., ... \&Alberti, K. G. (1978). Dietary fibres, fibre analogues, and glucose tolerance: importance of viscosity. Br Med J, 1(6124), 1392-1394.

[17]. Sharma, B. R., Naresh, L., Dhuldhoya, N. C., Merchant, S. U., \& Merchant, U. C. (2006). An overview on pectins. Times Food Processing Journal, 23(2), 44-51.

[18]. W. DeVries.(2004).Total Dietary Fiber. By Jonathan Ph.D Analytical Progrees Medallion Laboratories 
[19]. M.

Ravindrakullaireddy

and

KopparamManjunath. (2013).Pharmaceutical Applications of Natural Gums, Mucilages and Pectins - A Review .Inter .J . Pharm AndChemSci Vol. 2

[20]. Deogade, U. M., Deshmukh, V. N., \&Sakarkar, D. M. (2012). Natural Gums and Mucilage is in NDDS: Applications and Recent approaches. International Journal of PharmTech Research, 4(2), 799-814.

[21]. L.NagaVamsi Krishna. P.K. Kulkarni, Mudit Dixit, D.Lavanya, PrudhviKanthRaavi (2011). Brief Introduction of Natural Gums, MucilagesAnd Their Applications In Novel Drug Delivery System. Review Inter J. of Drug Formulation And Res.2011

[22]. Fleury, N., \&Lahaye, M. (1991). Chemical and physico-chemical characterisation of fibres from Laminariadigitata (kombubreton): A physiological approach. Journal of the Science of Food and Agriculture, 55(3), 389-400.23Gene A. Spiller .CRC HandBook of Dietary Fiber in Human Nutrition 3rd Edition Edited, California Boca Raton London New York Washington, D.C.CR

[23]. Torruco-Uco, J., Chel-Guerrero, L., \& Mart nez-Ayala, A. (2009). D vila-Ort z G. and Betancur-Ancona D. LWT-Food Sci. Technol, 42(10), 1597-1604.

[24]. Wong, J. M., \& Jenkins, D. J. (2007). Carbohydrate digestibility and metabolic effects. The Journal of nutrition, 137(11), 2539S-2546S.

[25]. Raghavarao, K. S. M. S., Raghavendra, S. N., \&Rastogi, N. K. (2008). Potential of coconut dietary fiber. Coconut Journal, 51(6), 2-7.

[26]. Frazzoli, A. (2007). Determination of hydration properties of insoluble plant material with different methods under physiological conditions (Doctoral dissertation, ETH Zurich).

[27]. Daou, C., \& Zhang, H. (2012). Study on functional properties of physically modified dietary fibres derived from defatted rice bran. Journal of Agricultural Science, 4(9), 85.

[28]. Abdul-Hamid, A., \& Luan, Y. S. (2000). Functional properties of dietary fibre prepared from defatted rice bran. Food chemistry, 68(1), 15-19.

[29]. Elleuch, M., Besbes, S., Roiseux, O., Blecker, C., Deroanne, C., Drira, N. E., \&Attia, H. (2008). Date flesh: Chemical composition and characteristics of the dietary fibre. Food chemistry, 111(3), 676-682.

[30]. Mudgil, D., \& Barak, S. (2013). Composition, properties and health benefits of indigestible carbohydrate polymers as dietary fiber: A review. International journal of biological macromolecules, 61, 1-6.

[31]. Rocı'oRodrı'guez. Ana Jime'nez, Juan Ferna'ndezBolanos, Rafael Guille'n and Antonia Heredia (2006). Dietary Fibre From Vegetable Products as Source of Functional Ingredients Trends in Food .Sci\& Tech

[32]. Azizah, A. H., \&Zainon, H. (1997). Effect of processing on dietary fiber contents of selected legumes and cereals. Malaysian Journal of Nutrition, 3(2), 131-136.

[33]. Shah, W. H. (2004). Domestic processing effects on some insoluble dietary fibre components of various food legumes. Food Chemistry, 87(4), 613-617.

[34]. Căpriță, A., Căpriță, R., Simulescu, V. O., \&Drehe, R. M. (2011). The effect of temperature on soluble dietary fiber fraction in cereals. J. of Agroalimentary Processes and Technol, 17(3), 214-217.

[35]. Ilelaboye, N. O. A., Amoo, I. A., \&Pikuda, O. O. (2013). Effect of cooking methods on proximate composition, gross energy and dietary fibre of some green leafy vegetables. Eur. J. of Appl. Eng. and Sci. Res, 2(2), 41-47.

[36]. Komolka, P., Górecka, D., \&Dziedzic, K. (2012). The effect of thermal processing of cruciferous vegetables on their content of 
dietary fiber and its fractions. ACTA ScientiarumPolonorumTechnologiaAlimentaria, 11(4), 347-354.

[37]. Yangilar, F. (2013). The application of dietary fibre in food industry: structural features, effects on health and definition, obtaining and analysis of dietary fibre: a review. Journal of Food and Nutrition Research, 1(3), 13-23.

[38]. Elleuch, M., Bedigian, D., Roiseux, O., Besbes, S., Blecker, C., \&Attia, H. (2011). Dietary fibre and fibre-rich by-products of food processing: Characterization, technological functionality and commercial applications: A review. Food chemistry, 124(2), 411-421.

[39]. Pinho, L. X., Afonso, M. R. A., Carioca, J. O. B., Costa, J. M. C. D., \& Ramos, A. M. (2011). The use of cashew apple residue as source of fiber in low fat hamburgers. Food Science and Technology, 31(4), 941-945.

[40]. Eldemery, M. E. (2010, April). Effect orange albedo as a new source of dietary fiber on characteristics of beef burger. In The 5th Arab and 2nd International Annual Scientific Conference on: Recent Trends of Developing Institutional and Academic Performance in Higher Specific Education Institutions in Egypt and Arab World. Mansoura University-Egypt (pp. 2406-2433).

[41]. McDonagh, C., Troy, D. J., Desmond, E., \& McDermott, H. (2004). Nutritional enhancement of meat products with dietary fibres. Teagasc.

[42]. Kurek, M., \&Wyrwisz, J. (2015). The application of dietary fiber in bread products. Journal of Food Processing and Technology, 6(5), 447-450.

[43]. Chang, R. C., Li, C. Y., \&Shiau, S. Y. (2015). Physico-chemical and sensory properties of bread enriched with lemon pomace fiber. Czech Journal of Food Sciences, 33(2), 180-185.

[44]. Sivam, A. S., Sun-Waterhouse, D., Quek, S., \&Perera, C. O. (2010). Properties of bread dough with added fiber polysaccharides and phenolic antioxidants: a review. Journal of food science, 75(8), R163-R174.

[45]. Chen, H., Rubenthaler, G. L., Leung, H. K., \&Baranowski, J. D. (1988). Chemical, physical, and baking properties of apple fiber compared with wheat and oat bran. Cereal Chem, 65(3), 244-247.

[46]. Majzoobi, M., Habibi, M., Hedayati, S., Ghiasi, F., \&Farahnaky, A. (2015). Effects of commercial oat fiber on characteristics of batter and sponge cake.)

[47]. Goldstein, A., Ashrafi, L., \&Seetharaman, K. (2010). Effects of cellulosic fibre on physical and rheological properties of starch, gluten and wheat flour. International journal of food science \& technology, 45(8), 1641-1646.49- I. B. Hashim

[48]. Hashim, I. B., Khalil, A. H., \&Afifi, H. S. (2009). Quality characteristics and consumer acceptance of yogurt fortified with date fiber. Journal of dairy science, 92(11), 5403-5407.

[49]. Ibrahim, A. H., \&Khalifa, S. A. (2015). Improve sensory quality and textural properties of fermented camel's milk by fortified with dietary fiber. J. Am. Sci, 11(3), 42-54.

[50]. Guo, Qingbin, et al. "Dietary Fiber: Chemistry, Structure, and Properties." Journal of Chemistry 2018 (2018).

[51]. Dabija, A., Codină, G. G., Gâtlan, A. M., \&Rusu, L. (2018). Quality assessment of yogurt enriched with different types of fibers. CyTAJournal of Food, 16(1), 859-867.

[52]. Akalın, A. S., Kesenkas, H. A. R. U. N., Dinkci, N. A. Y. İ. L., Unal, G. Ü. L. F. E. M., Ozer, E. L. İ. F., \&Kınık, O. (2018). Enrichment of probiotic ice cream with different dietary fibers: Structural characteristics and culture viability. Journal of dairy science, 101(1), 37-46.

[53]. Makhlouf, S., Jones, S., Ye, S. H., SanchoMadriz, M., Burns-Whitmore, B., \& Li, Y. O. (2019). Effect of selected dietary fibre sources 
and addition levels on physical and cooking quality attributes of fibre-enhanced pasta. Food Quality and Safety, 3(2), 117-127.

\section{Cite this article as :}

Ahmed M A Hamad, "Evaluation of Dietary Fiber and the Effect on Physicochemical Properties of Foods", International Journal of Scientific Research in Science and Technology (IJSRST), Online ISSN : 2395-602X, Print ISSN : 2395-6011, Volume 8 Issue 3, pp. 421-433, May-June 2021. Available at doi : https://doi.org/10.32628/IJSRST218385

Journal URL : https://ijsrst.com/IJSRST218385 